\title{
Fluid Flow Analysis of Jets from Nozzles in Top Blown Process
}

\author{
Yukari TAGO and Yoshihiko HIGUCHI \\ Corporate Research \& Development Laboratories, Sumitomo Metal Industries, Ltd., Oaza-Sunayama, Hasakimachi, Kashima- \\ gun, Ibaraki 314-0255 Japan.
}

(Received on August 5, 2002; accepted in final form on October 2, 2002)

\begin{abstract}
It is important to know the behavior of jets from a top blown lance in order to control the refining and spitting phenomena of the converter in the steelmaking process. However, there are few theoretical studies on the characteristics of the jets from the nozzles.

In the present study, the characteristics of jets from single-nozzle and multi-nozzle lances were investigated by a fluid flow analysis based on fluid dynamics. The accuracy of the analysis was confirmed with the results of the cold model experiments.

As a result, it is clarified that the dynamic pressures of the jets from the single-nozzle or multi-nozzle lances are in a good agreement with those in the cold model experiments and are influenced by the nozzle geometry such as the inclination angle and the number of nozzles. It is also clarified that the jets from the nozzles proceed the different paths from those obtained geometrically due to coalescence between the jets.
\end{abstract}

KEY WORDS: converter; lance; nozzle; jet; spitting; inclination angle; dynamic pressure; fluid dynamics.

\section{Introduction}

In steelmaking processes such as BOF and combination blowing, oxygen is supplied to the molten iron through nozzles in the form of a gas jet for decarburization. The present authors reported in an earlier paper ${ }^{1)}$ that the top blown jets influence the decarburization rate and (T.Fe) in slag in the final stage of the processes. The gas jet tears off the liquid and generates droplets. These phenomena are generally referred to as "spitting" or "splash" and they have been researched by many researchers ${ }^{2-10}$ ) because they are causes of operational problems and lead to lower productivity and lower metallic recovery in the commercial plants. Therefore, it is necessary to control the behavior of the jets from nozzle exits to improve the decarburization rate, reduce (T.Fe) in slag and decrease "spitting" or "splash" by designing the lance shape properly.

In many researches, ${ }^{11-14)}$ the behavior of the single jet or the multiple jets have been investigated from an experimental point of view. There exist some problems even on the simple single jet, which is composed of the core region and the region of similarity. The length of the core region is referred to as "core length" and it is very important to know it to estimate the characteristics of the jets. However, the different values are reported as "core length" by some researchers. Moreover, it is necessary to know the multiple jets behavior because the recent converters are operated invariably using multi-nozzle lances such as lances with 4 or more nozzles of Laval type (convergent-divergent type). There are different problems in the multiple jets derived from the fact that the multiple jets are easy to coalesce with one another and that the phenomena of coalescence are very difficult to predict.

As mentioned above, it is important and necessary to know the jet behavior and they have been investigated by many researchers experimentally, for example, using a small size model and a Pitot tube. The measurements are effective to know the jet behavior directly, but it is very difficult to predict it on a commercial basis. Naito et al. ${ }^{14)}$ performed the experiments on the interference of multiple jets using two straight-type lances with a single nozzle and simulated the behavior based on the simple calculation assuming the conservation of momentum. It is reported that it is sufficient to understand the coalescence behavior between just the two jets. However, they did not mention the way to estimate the complex interference behavior of the multiple jets from 4 or more nozzles. The method to estimate the multiple jets behavior with a high accuracy has not been established. Therefore, the lance shapes in the commercial plants have been designed empirically.

In the present study, the jet behavior was modeled based on the fluid dynamics and the calculated results were confirmed with the observed ones. The model simulations were applied to a variety of lances on a commercial basis and the effects of the number and the inclination angle of the nozzles were clarified.

\section{Experiment}

\subsection{Experimental Method}

Experiments were carried out with a cold model shown in Fig. 1 using oxygen gas as in the commercial converters. The dynamic pressures of the jets were measured with a Pitot tube (JIS B-8330) set as shown in Fig. 1. The Pitot 


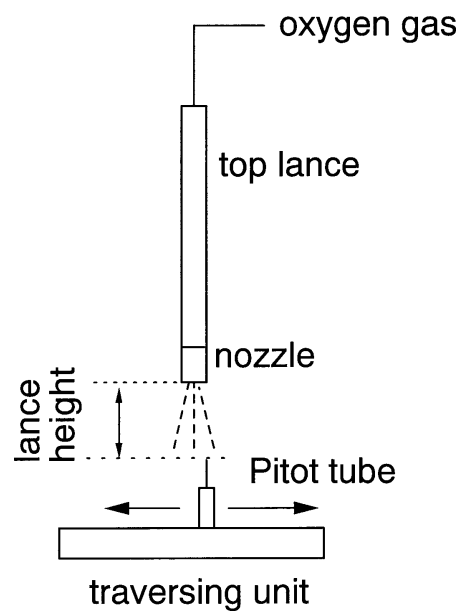

Fig. 1. Experimental apparatus for dynamic pressure measurement.

Table 1. Experimental conditions for cold model.

\begin{tabular}{|c|c|c|c|}
\hline $\begin{array}{c}\text { number } \\
\text { of nozzle } \\
(-)\end{array}$ & $\begin{array}{c}\text { throat } \\
\text { diameter } \\
(\mathrm{mm})\end{array}$ & $\begin{array}{c}\text { oxygen } \\
\text { flow rate } \\
\left(\mathrm{Nm}^{3} / \mathrm{s}\right)\end{array}$ & $\begin{array}{c}\text { inclination } \\
\text { angle } \\
(\mathrm{deg} .)\end{array}$ \\
\hline 1 & 4.5 & $1.05 \times 10^{-2}$ & 0 \\
\hline 1 & 9.0 & $4.23 \times 10^{-2}$ & 0 \\
\hline 4 & 6.6 & $1.00 \times 10^{-1}$ & 10,15 \\
\hline
\end{tabular}

tube was set on a slender stand and the distance from the tip to the traversing unit was about $400 \mathrm{~mm}$. Therefore the effect of the reversal flow could be ignored. The pressure outputs of the tube were transformed into the voltage signals, converted into the digital signals and finally stored in the memory of a personal computer. The measured pressures were time-averaged to cancel the errors resulting from the fluctuation, which was considered to be caused by turbulent flow. Generally, it is difficult to estimate time-averaged values by measuring without such a pressure transducer, for example, by measuirng with a $U$ tube, which was used for the most of previous studies.

Experiments were performed using single-nozzle and multi-nozzle lances of Laval type (convergent-divergent type) as in the commercial converters. The experiments of the single-nozzle lances were performed under the condition that the throat diameters of the lances are 4.5 and $9.0 \mathrm{~mm}$ and the oxygen gas flow rate were $1.05 \times 10^{-2}$ and $4.23 \times 10^{-2} \mathrm{Nm}^{3} / \mathrm{s}$, respectively. 4-nozzle lances were used as a multi-nozzle type. The throat diameter of the lances was $6.6 \mathrm{~mm}$, the oxygen gas flow rate was $0.1 \mathrm{~m}^{3}$ (normal)/s and the angle of the nozzle inclination was 10 or 15 degrees.

The conditions for the cold model experiments are listed in Table 1. They satisfy the following correct expansion condition on a theoretical basis. ${ }^{14)}$

$$
\begin{aligned}
& (d t / d e)^{2}=0.259 /\left[\left(P^{*} / P o\right)^{5 / 7} \cdot\left\{1-\left(P^{*} / P o\right)^{2 / 7}\right\}^{1 / 2}\right] . \\
& Q=1.29 \times 10^{-6} \cdot n \cdot d t^{2} \cdot P o .
\end{aligned}
$$

where $d t$ : the throat diameter of the nozzle $(\mathrm{mm}), d e$ : the exit diameter of the nozzle $(\mathrm{mm}), P^{*}$ : the reference pressure $\left(1.013 \times 10^{2} \mathrm{kPa}\right), P_{0}$ : the pressure at nozzle inlet $(\mathrm{kPa}), Q$ : the oxygen flow rate $\left(\mathrm{Nm}^{3} / \mathrm{s}\right)$ and $n$ : the number of the nozzles $(-)$.

\section{Numerical Analysis}

\subsection{Fundamental Equations and Method of Calcula- tion}

The equation for conservation of mass or the continuity equation, can be written as follows:

$$
\partial \rho / \partial t+\partial\left(\rho \cdot U_{i}\right) / \partial X_{i}=0 \text {. }
$$

where $\rho$ : the density of fluid $\left(\mathrm{kg} / \mathrm{m}^{3}\right), U_{i}$ : the mean velocity component in the $i$ th direction $(\mathrm{m} / \mathrm{s})$.

The equation for conservation of momentum in the $i$ direction can be written as follows:

$$
\begin{aligned}
& \partial\left(\rho U_{i}\right) / \partial t+\partial\left(\rho \cdot U_{i} \cdot U_{i}\right) / \partial X_{i} \\
&=-\partial P / \partial X_{i}+\partial \tau_{i j} / \partial X_{j}+\rho \cdot g_{i}+F_{i} \ldots . \\
& \tau_{i j}= \mu\left(\partial U_{i} / \partial X_{j}+\partial U_{j} / \partial X_{i}\right) \\
&-(2 \mu / 3) \cdot\left(\partial U_{k} / \partial X_{k}\right) \delta_{i j}-\rho \overline{U_{i}^{\prime} U_{j}^{\prime}}
\end{aligned}
$$

where $P$ : the pressure of fluid $(\mathrm{Pa}), g_{i}$ : the gravity acceleration in the $i$ direction $\left(\mathrm{m} / \mathrm{s}^{2}\right), F_{i}$ : the external body force in the $i$ direction $\left(\mathrm{N} / \mathrm{m}^{3}\right), \mu$ : the molecular viscosity $(\mathrm{kg} / \mathrm{m} \cdot \mathrm{s})$ and $U_{i}^{\prime}$ : the instantaneous velocity component in the $i$ direction $(\mathrm{m} / \mathrm{s})$.

$-\rho \overline{U_{i}^{\prime} U_{j}^{\prime}}$, the third term in the right-hand of Eq. (5), is referred to as "Reynolds stresses" to represent the effects of the turbulence and must be modeled as mentioned later.

The energy equation for the turbulent heat transport is expressed with Eq. (6) using the concept of Reynolds' analogy to the turbulent momentum transfer.

$$
\begin{aligned}
& \partial(\rho E) / \partial t+\partial\left[U_{i}(\rho E+P)\right] / \partial X_{i} \\
& =-\partial\left[\left(k^{\prime}+C_{p} \mu_{\mathrm{t}} / \operatorname{Pr}_{\mathrm{t}}\right) \partial T / \partial X_{i}+U_{j}\left(\tau_{i j}\right)_{\mathrm{eff}}\right] / \partial X_{i} . \\
& \left(\tau_{i j}\right)_{\mathrm{eff}}=\mu_{\mathrm{eff}}\left(\partial U_{i} / \partial X_{j}+\partial U_{j} / \partial X_{i}\right) \\
& -\left(2 \mu_{\mathrm{eff}} / 3\right) \cdot\left(\partial U_{i} / \partial X_{i}\right) \delta_{i j}
\end{aligned}
$$

where $E$ : the total energy $(\mathrm{J}), k^{\prime}$ : the thermal conductivity of the fluid $(\mathrm{W} / \mathrm{m} \cdot \mathrm{K}), C_{p}$ : the specific heat $(\mathrm{J} / \mathrm{kg} \cdot \mathrm{K}), \operatorname{Pr}_{\mathrm{t}}$ : the turbulent Prandtl number $(-), T$ : the temperature of the fluid $(\mathrm{K}), \mu_{\mathrm{t}}$ : the turbulent viscosity $(\mathrm{kg} / \mathrm{m} \cdot \mathrm{s})$ and $\mu_{\text {eff }}$ : the effective viscosity $(\mathrm{kg} / \mathrm{m} \cdot \mathrm{s})$.

\subsection{Turbulence Models}

Two kinds of turbulence models, $\kappa-\varepsilon$ model $^{15)}$ and Reynolds Stress Model (RSM), ${ }^{16)}$ were employed to take the effect of turbulence on the fluid flow into consideration.

\subsubsection{The $\kappa-\varepsilon$ Model}

In the $\kappa-\varepsilon$ model, the Reynolds stresses are related to the mean velocity gradients on the basis of the Boussinesq hypothesis as follows:

$$
\begin{aligned}
-\rho \overline{U_{i}^{\prime} U_{j}^{\prime}},= & \mu_{\mathrm{t}}\left(\partial U_{i} / \partial X_{j}+\partial U_{j} / \partial X_{i}\right) \\
& -(2 / 3) \cdot\left(\rho \kappa+\mu_{\mathrm{t}} \partial U_{i} / \partial X_{i}\right) \delta_{i j}
\end{aligned}
$$

where $\kappa$ : the turbulent kinetic energy $\left(\mathrm{m}^{2} / \mathrm{s}^{2}\right)$.

In the $\kappa-\varepsilon$ model, ${ }^{15)}$ the turbulent kinetic energy, $\kappa$, and its rate of dissipation, $\varepsilon$, are obtained from the following transport equations:

$$
\begin{aligned}
\rho D \kappa / D t= & \partial\left[\left(\mu+\mu_{\mathrm{t}} / \sigma_{\kappa}\right) \partial \kappa / \partial X_{i}\right] / \partial X_{i} \\
& +G_{\kappa}-\rho \cdot \varepsilon\left(1+2 \kappa / a^{2}\right) \ldots \ldots .
\end{aligned}
$$




$$
\begin{gathered}
\rho D \varepsilon / D t=\partial\left[\left(\mu+\mu_{\mathrm{t}} / \sigma_{\varepsilon}\right) \partial \varepsilon / \partial X_{i}\right] / \partial X_{i} \\
+C_{1 \varepsilon} \cdot(\varepsilon / \kappa) \cdot G_{\kappa}-C_{2 \varepsilon} \cdot \rho \cdot \varepsilon^{2} / \kappa \ldots \\
G_{\kappa}=\mu_{\mathrm{t}} \cdot\left(\partial U_{i} / \partial X_{j}+\partial U_{j} / \partial X_{i}\right) \cdot\left(\partial U_{i} / \partial X_{j}+\partial U_{j} / \partial X_{i}\right) / 2 .
\end{gathered}
$$

where $a$ : the speed of sound (m/s), $C_{1 \varepsilon}, C_{2 \varepsilon}$ : the model constants, $\sigma_{\kappa}, \sigma_{\varepsilon}$ : the turbulent Prandtl numbers for $\kappa, \varepsilon$.

The turbulent viscosity, $\mu_{\mathrm{t}}$, can be written as follows:

$$
\mu_{\mathrm{t}}=\rho \cdot C_{\mu} \cdot \kappa^{2} / \varepsilon
$$

$C_{1 \varepsilon}, C_{2 \varepsilon}, C_{\mu}, \sigma_{\kappa}, \sigma_{\varepsilon}$ are constants for $\kappa-\varepsilon$ model and the values of them are $1.44,1.92,0.09,1.0$ and 1.3 , respectively. ${ }^{15)}$

The $\kappa-\varepsilon$ model has been successful in simulating a variety of turbulent flows with the relatively low computational power and time. However, it is known to give a worse accuracy in some cases because it assumes $\mu_{\mathrm{t}}$ is an isotropic scalar quantity.

\subsubsection{Reynolds Stress Model}

To prevent the disadvantage of the $\kappa-\varepsilon$ model, the present authors adopt the alternative approach, the Reynolds Stress Model (RSM), ${ }^{16)}$ which solves transport equations for each of the terms in the Reynolds stress tensor. RSM is clearly superior for situations in which the anisotropy of turbulence has a dominant effect on the mean flow. The better accuracy of RSM is advantageous to predict the jet behavior whereas the disadvantage of RSM is the relatively high computational cost.

In the RSM, the equations for the transport of the Reynolds stresses, $-\rho \overline{U_{i}^{\prime} U_{j}^{\prime}}$, can be written as follows:

$$
\begin{aligned}
& \partial\left(\rho \overline{U_{i}^{\prime} U_{j}^{\prime}}\right) / \partial t+C_{i j}=D_{i j}+p_{i j}+\phi_{i j}-e_{i j} \\
& C_{i j}=\partial\left(\rho U_{k} \overline{U_{i}^{\prime} U_{j}^{\prime}}\right) / \partial X_{k} . \\
& D_{i j}=-\partial\left(\rho \overline{U_{i}^{\prime} U_{j}^{\prime} U_{k}^{\prime}}+\overline{P\left(\delta_{k j} U_{i}^{\prime}+\delta_{i k} U_{j}^{\prime}\right)}\right) / \partial X_{k} \\
& +\partial\left(\mu \partial \overline{U_{i}^{\prime} U_{j}^{\prime}} / \partial X_{k}\right) / \partial X_{k} \\
& p_{i j}=-\rho\left(\overline{U_{i}^{\prime} U_{k}^{\prime}} \partial U_{i} / \partial X_{k}+\overline{U_{j}^{\prime} U_{k}^{\prime}} \partial U_{j} / \partial X_{k}\right) \text {. } \\
& \phi_{i j}=\overline{P\left(\partial U_{i}^{\prime} / \partial X_{j}+\partial U_{j}^{\prime} / \partial X_{i}\right)} \\
& e_{i j}=-2\left(\mu \overline{\partial U_{i}^{\prime} / \partial X_{k} \cdot \partial U_{j}^{\prime} / \partial X_{k}}\right)
\end{aligned}
$$

The terms $D_{i j}, \phi_{i j}$ and $e_{i j}$ need to be modeled to close the equations as follows:

$$
\begin{aligned}
D_{i j}= & \partial\left\{\left(\mu+\mu_{\mathrm{t}} / \sigma_{\mathrm{t}}\right) \partial \overline{U_{i}^{\prime} U_{j}^{\prime}} / \partial X_{k}\right\} / \partial X_{k} \ldots \ldots \ldots .(19)^{17)} \\
\phi_{i j}= & -C_{1} \rho(\varepsilon / \kappa)\left\{\overline{U_{i}^{\prime} U_{j}^{\prime}}-(2 / 3) \delta_{k j j}\right\} \\
& -C_{2}\left\{p_{i j}-C_{i j}-\left(p_{k k}+C_{k k}\right) \delta_{i j} / 3\right\} \ldots \ldots \ldots(20)^{18)} \\
& e_{i j}=(2 / 3) \delta_{i j} \rho \cdot \varepsilon\left(1+2 \kappa / a^{2}\right) \ldots \ldots \ldots \ldots \ldots(21)^{19)}
\end{aligned}
$$

$\sigma_{\mathrm{t}}, C_{1}$ and $C_{2}$ are empirically derived constants, $0.82,1.8$ and 0.6 , respectively. ${ }^{17,18)}$

\subsection{Boundary Conditions}

Mass flow boundary condition was employed at the gas inlet. The inlet pressure was adjusted locally to achieve the velocity needed to provide the prescribed mass flow rate. For the boundary condition of the walls, the wall function was employed. The pressure outlet boundary condition was employed and the value of static pressure was specified at the outlet boundary. For the symmetry plane, symmetry

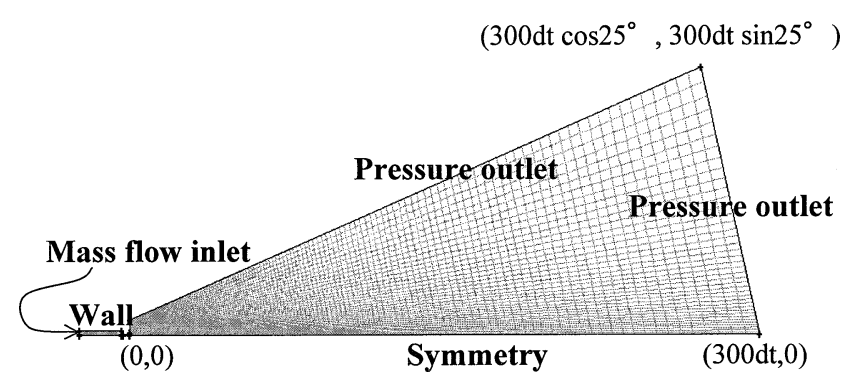

Fig. 2. Grid configuration for calculation of single-nozzle lance.

Table 2. Conditions for calculation.

\begin{tabular}{|c|c|c|c|c|}
\hline $\begin{array}{c}\text { number } \\
\text { of nozzle } \\
(-)\end{array}$ & $\begin{array}{c}\text { throat } \\
\text { diameter } \\
(\mathrm{mm})\end{array}$ & oxygen flow rate & $\begin{array}{c}\text { inclination } \\
\text { angle } \\
(\mathrm{Nm} / \mathrm{s})\end{array}$ & $\begin{array}{c}\text { ambient } \\
\text { temperature } \\
(\mathrm{K})\end{array}$ \\
\hline 1 & 4.5 & $1.05 \times 10^{-2}$ & 0 & 300,1061 \\
\hline 1 & 9.0 & $4.23 \times 10^{-2}$ & 0 & 300 \\
\hline 1 & 5.0 & $1.58 \times 10^{-2}-3.16 \times 10^{-2}$ & 0 & 300 \\
\hline 1 & 10.0 & $6.33 \times 10^{-2}-1.27 \times 10^{-1}$ & 0 & 300 \\
\hline 1 & 15.0 & $1.42 \times 10^{-1}-2.85 \times 10^{-1}$ & 0 & 300 \\
\hline 1 & 30.0 & $5.69 \times 10^{-1}-1.14$ & 0 & 300 \\
\hline 1 & 45.0 & $1.28-2.56$ & 0 & 300 \\
\hline 4 & 6.6 & $1.00 \times 10^{-1}$ & 10,15 & 300 \\
\hline 4 & 55.0 & 15.3 & $10,15,20$ & 300 \\
\hline 6 & 44.9 & 15.3 & 20 & 300 \\
\hline
\end{tabular}

boundary condition was used where there was no convective flux, zero normal velocity, zero normal gradients of all variables and zero shear stress. Two dimensional grid configuration was shown for a single-nozzle lance as an example in Fig. 2. The conditions for computation were listed in Table 2. They satisfy the correct expansion condition mentioned above.

\section{Results and Discussion}

\subsection{Jets from Single-nozzle Lances}

The jet behavior from the single-nozzle lances $(d t=4.5$ $\mathrm{mm}, 9.0 \mathrm{~mm}$ ) was calculated to be compared with the experimental results under the condition that the ambient temperature was equal to the room temperature. The calculations were performed with the $\kappa-\varepsilon$ model as the turbulence model because the calculated results were not affected by the kind of the turbulence model in the case of the jets from single-nozzle lances. The dynamic pressures of the jets along the axis were plotted against the distance from the exits of the nozzles with $d t=4.5 \mathrm{~mm}$ and $9.0 \mathrm{~mm}$ in Fig. 3 . The observed and calculated pressures are represented by the closed marks and lines, respectively. This figure shows that the calculated pressures keep constant to some extent of distance from the nozzle exits and thereafter decrease gradually and that the calculated values show a good agreement with the observed ones.

The core length of the jet from the single-nozzle lance, $X c(\mathrm{~mm})$, has been measured by some researchers and the values are formulated as follows:

$$
X c / d e=2.47\left(P_{0} / P^{*}\right) \text {.. }
$$

$$
X c / d t=4.12\left\{\left(P_{0} / P^{*}\right)-1\right\}-1.86
$$

$X c / d t=M o\left(5.88+1.54 M o^{2}\right), M o=\left[5\left\{\left(P_{0} / P^{*}\right)^{2 / 7}-1\right\}\right]^{1 / 2}$ 


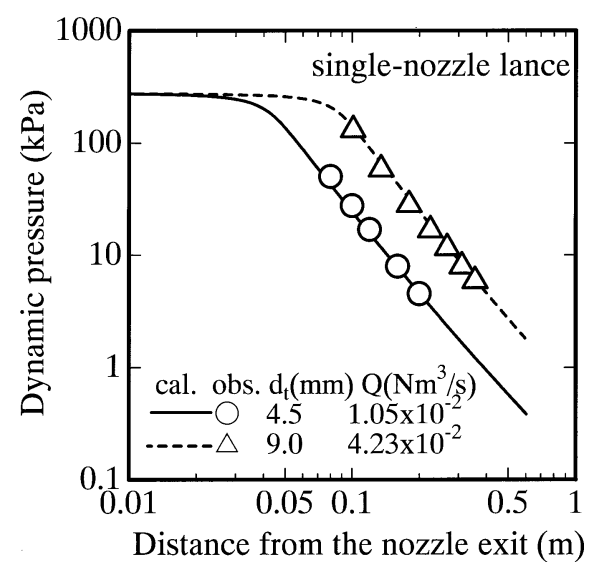

Fig. 3. Dynamic pressure of single jet along the axis $(d t=4.5$ $\mathrm{mm}, 9.0 \mathrm{~mm})$

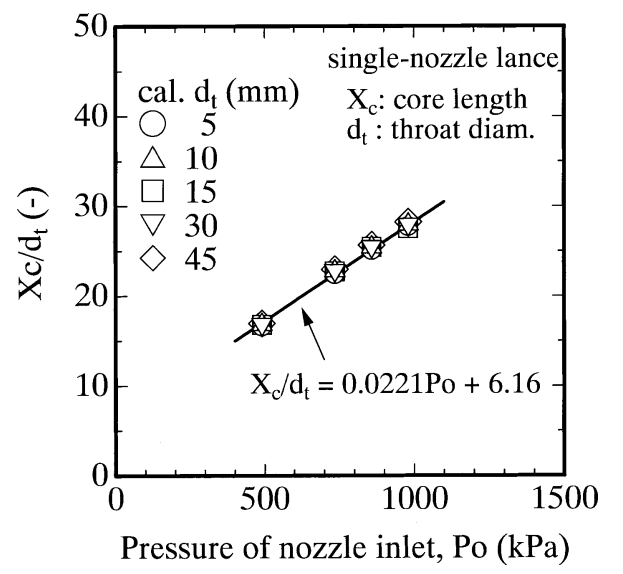

Fig. 4. Relation between core length and inlet pressure.

The core lengths mentioned above did not coincide with one another and it is unknown which empirical equation is accurate. Then it is necessary to estimate the core length by comparing with the calculated results. The core length was decided from the calculated results and were plotted against the inlet pressures in Fig. 4. The core length was defined as the distance from the nozzle tip to the point where the Mach number is unity based on the literature by earlier researchers. ${ }^{14)}$ Figure 4 shows that the normalized core lengths, $X c / d t$, are little affected by the throat diameter, $d t$. Regression analysis was applied to the calculated results and Eq. (25) was obtained as the empirical equation.

$$
X c / d t=2.24\left(P o / P^{*}\right)+6.16
$$

The normalized core length " $X c / d t$ " given in Eqs. (22)(25) was plotted against the inlet pressure for the comparison in Fig. 5. Because the core length was given as " $X c / d e$ " in Eq. (22) proposed by Kawakami, ${ }^{13)}$ the value was converted into " $X c / d t$ " using Eq. (1). The present work was in a good accordance with that by Naito et al. ${ }^{14)}$ The obtained equation in the present work is more convenient for estimating the core length as far as $P O$ is from 500 to $1000 \mathrm{kPa}$ because it gives a simpler expression than Eq. (24) proposed by Naito et al.

On the other hand, the expressions proposed by Shimada et $a{ }^{12)}$ and Kawakami ${ }^{13)}$ showed different relationship from the present work. As a reason for the difference, it is thought that they did not pay any attention to the errors re-

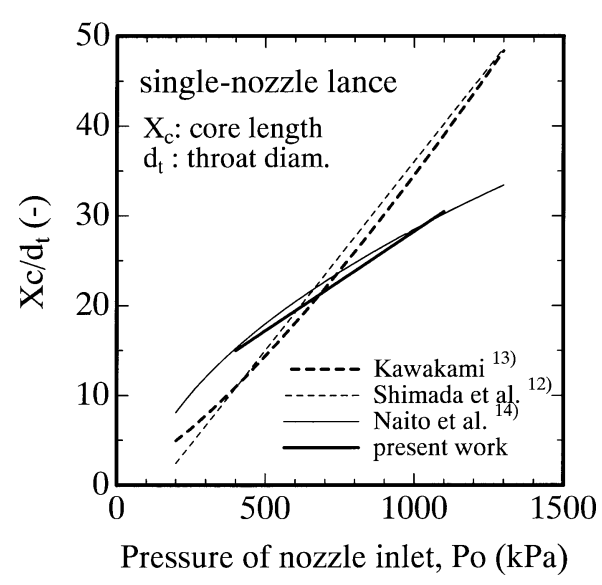

Fig. 5. Relation between core length and inlet pressure.

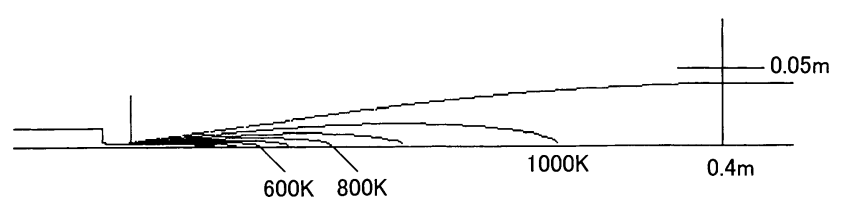

Fig. 6. Contour map of gas temperature.

sulting from the fluctuation of the dynamic pressure.

\subsection{Effect of the Ambient Temperature on the Jet Behavior}

In the steelmaking processes such as BOF and combination blowing, oxygen gas jets with low temperature are supplied to the melt through the hot atmosphere and the gas jets are heated before reaching the bath surface. It is predicted that the gas heating process gives much effect on the jet behavior due to the drastic change of the properties, for example, gas density. However, there are very little reports concerning the effect of ambient temperature on the jet behavior because accurate measurement of the jet behavior including gas temperature is very difficult. ${ }^{20)}$

Then, in this section, the effect of ambient temperature on the jet behavior is estimated by the fluid flow analysis. Calculations are performed under the condition that the nozzle is Laval type with a single-nozzle, the throat diameter is $4.5 \mathrm{~mm}$, the inlet gas temperature is $300 \mathrm{~K}$. The ambient temperature is chosen to be $300 \mathrm{~K}$ as low temperature and $1061 \mathrm{~K}$ as an example for hot atmosphere according to the literature. ${ }^{20)}$ The calculations are also performed with $\kappa-\varepsilon$ model because the results were not affected by the kind of the turbulence model as in the previous section. The calculated temperature distribution of the gas jet is shown in Fig. 6. The figure shows that the temperature of the gas jet increases from the inlet temperature gradually after the discharge from the nozzle exit.

The calculated density, axial velocity and dynamic pressure of the jets along the axis are plotted against the distance from the nozzle exit in Figs. 7, 8 and 9, respectively. The calculated results under the constant room temperature are also plotted in the figures for the comparison. Figure 7 shows that the density of the gas decreases just after discharge from the nozzle exit and reaches the constant value corresponding to the ambient temperature. The line for the higher ambient temperature indicates the lower density due to the thermal volume expansion of the gas. Figure 8 shows 


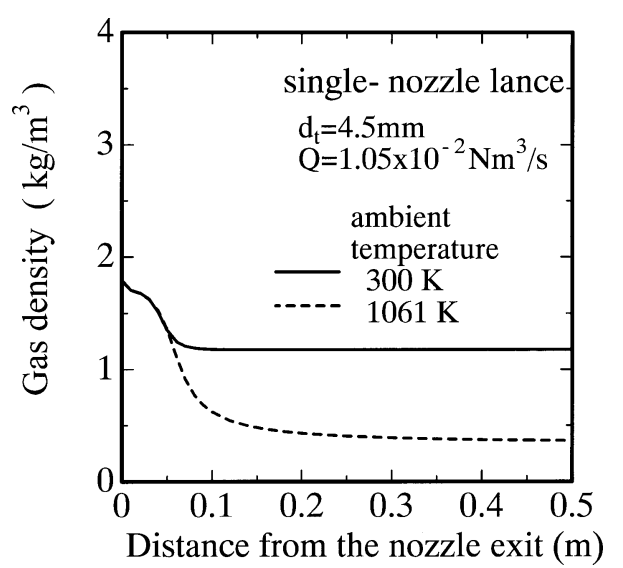

Fig. 7. Relation between gas density and distance from nozzle exit.

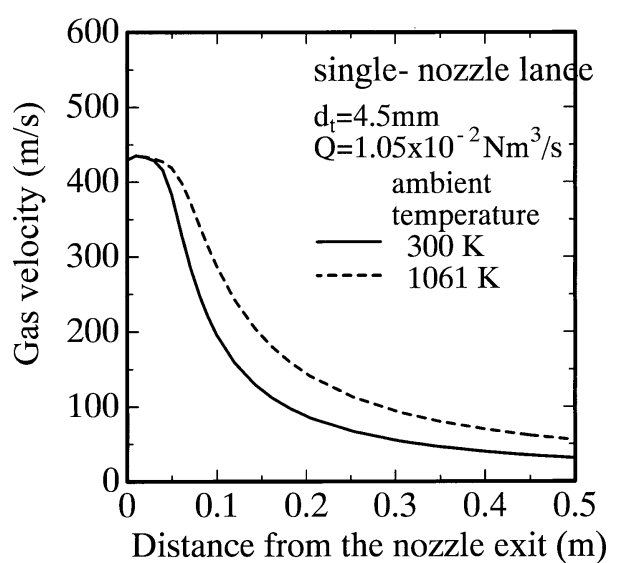

Fig. 8. Relation between gas velocity and distance from nozzle exit.

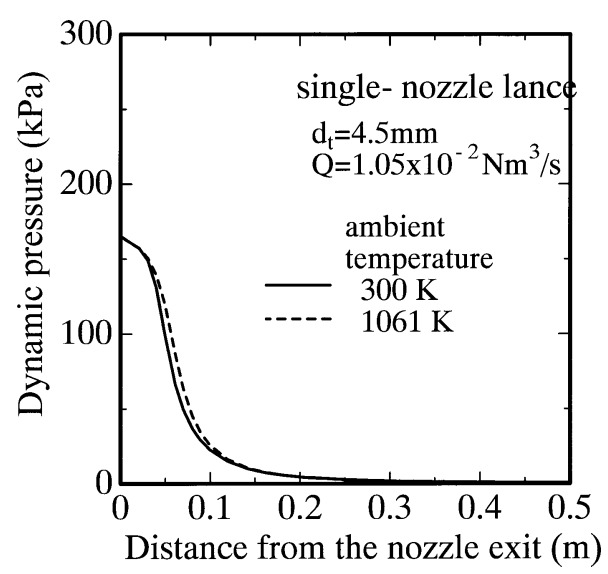

Fig. 9. Relation between dynamic pressure and distance from nozzle exit.

that the velocity of the gas keeps constant just after the nozzle exit and decreases at the different rate according to the ambient temperature. The line for the hotter atmosphere indicates the higher velocity due to the lower density of the gas and the same behavior are also reported by the other researcher. $^{20)}$

As mentioned above, it is clear that the ambient temperature gives much effect on the density and velocity of the gas. However, the dynamic pressure is more important as the characteristics of the gas jets because the velocity and

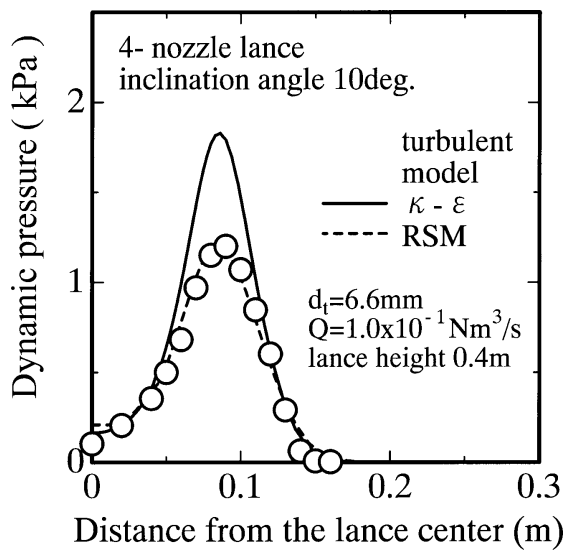

Fig. 10. Relation between dynamic pressure and distance from lance center.

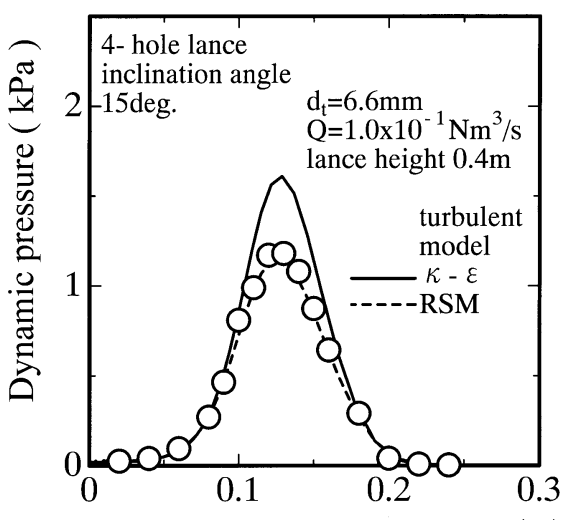

Distance from the lance center $(\mathrm{m})$

Fig. 11. Relation between dynamic pressure and distance from lance center.

density do not represent the impact of the jets on the metal surface by themselves. Figure 9 shows that the dynamic pressure decreases gradually after discharge from the nozzle exit and that the values are little affected by the ambient temperature. It is suggested that it is little necessary to take the ambient temperature into consideration to estimate the dynamic pressures of the jets.

\subsection{Jets from Multi-nozzle Lances}

The dynamic pressures of the jets from the 4-nozzle lance $(d t=6.6 \mathrm{~mm})$ on the plane $0.4 \mathrm{~m}$ distant from the nozzle tip were plotted against the distance from the lance axis in Figs. 10 and 11. The calculations were performed with both the $\kappa-\varepsilon$ model and the RSM as the turbulence model for the comparison. Figures 10 and 11 show that the calculated results based on RSM are in a better agreement with the observed ones than those based on the $\kappa-\varepsilon$ model. It is suggested that the anisotropy of tuburlence could not be ignored in the multiple jets.

\subsection{Simulation for Jets from Lances with 4- or 6- Nozzles of Commercial Scale}

The jet behavior of top blown process on a commercial basis have not been known or observed due to the difficulty of measurement. Then the hot spot geometry of the top blown jets has been expected assuming that the jet proceeds straight and spreads with a given cone angle. ${ }^{8,9)}$ However, it is clear that such geometrical calculations are not enough to 
(a)

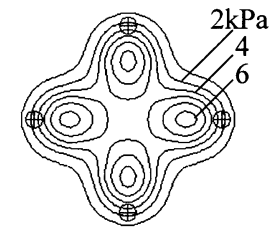

(b)

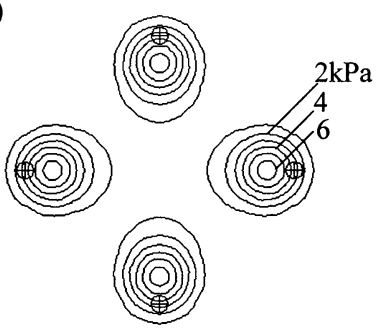

(c)
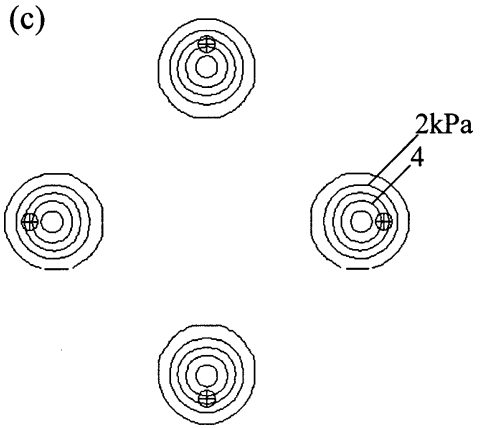

Fig. 12. Contour map of dynamic pressure on the plane $3.0 \mathrm{~m}$ distant from nozzle exit (4-nozzle lance). (a) Inclination angle: 10 degrees, (b) inclination angle: 15 degrees, (c) inclination angle: 20 degrees.

predict the jet behavior because they ignore the coalescence of the jets and so on.

As mentioned above, the present authors established the fluid flow analysis method of the multiple jets and indicated that the method was very useful for prediction of the jet behavior. Then the jet behavior in the top blown process on a commercial basis were simulated as an application of the method. 4- or 6-nozzle lances were used with inclination angles of 10-20 degrees. The throat diameters were 55.0 $\mathrm{mm}$ and $44.9 \mathrm{~mm}$ for 4 - and 6-nozzle lances, respectively. The oxygen gas flow rate and the lance height were selected to be $15.3 \mathrm{Nm}^{3} / \mathrm{s}$ and $3.0 \mathrm{~m}$ as a typical condition of the commercial converters with high productivity.

Figure 12 shows the contour maps of the dynamic pressure on the plane $3.0 \mathrm{~m}$ distant from the nozzle tip of 4-nozzle lances. The calculated results for the inclinations of 10 , 15 and 20 degrees were plotted in Figs. 12(a), 12(b) and 12(c), respectively. The marks $(+)$ in the figures indicate the centers of the hot spots based on the simple geometrical calculation assuming that the jets from the nozzle tips go straight without coalescence.

The figures also indicate that the coalescence of the jets remarkably occurs in the lance with the inclination of 10 degrees and scarcely does in the lance with the inclination of 20 degrees. The paths of the center of the jets were plotted in Fig. 13 to clarify the effect of the nozzle angle on the coalescence quantitatively. The marks in the figures indi-

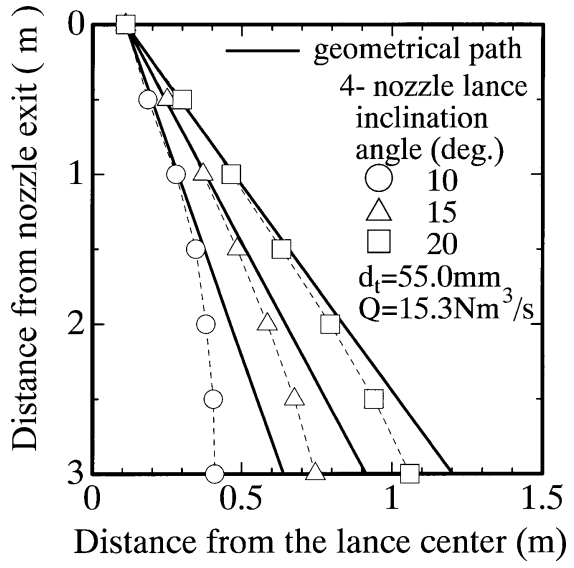

Fig. 13. Effect of inclination angle on the jet paths (4-nozzle lance).

(a)
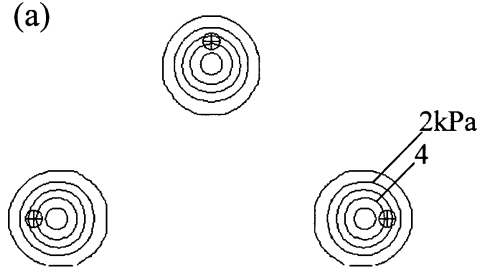

(b)

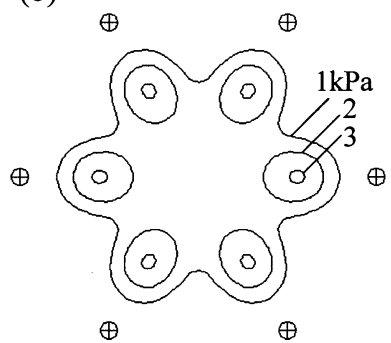

Fig. 14. Contour map of dynamic pressure on the plane $3.0 \mathrm{~m}$ distant from the nozzle exit (inclination angle: 20 degrees). (a) 4-nozzle lance, (b) 6-nozzle lance.

cate the centers of the hot spots calculated with the fluid flow analysis and the lines indicate the results of the simple geometrical calculation. The figure shows that the 4-nozzle lances with the lower inclination angle result in the higher deviation from the simple geometrical calculation and are more likely to lead to the jet coalescence.

Figure 14 shows the contour maps of the dynamic pressure on the plane $3.0 \mathrm{~m}$ distant from the nozzle tip of 4- and 6-nozzle lances with the same inclination angle of 20 degrees. The marks $(+)$ indicate the centers of the hot spots based on the simple geometrical calculation. The figure shows that the jets from the 6-nozzle lance are likely to coalesce with one another compared with the jets from the 4nozzle lance. The paths of the center of the jets were plotted in Fig. 15. The marks indicate the centers of the hot spots based on the fluid flow analysis and the lines indicate the results of the simple geometrical calculation. The figure shows that 6-nozzle lance results in the higher deviation 


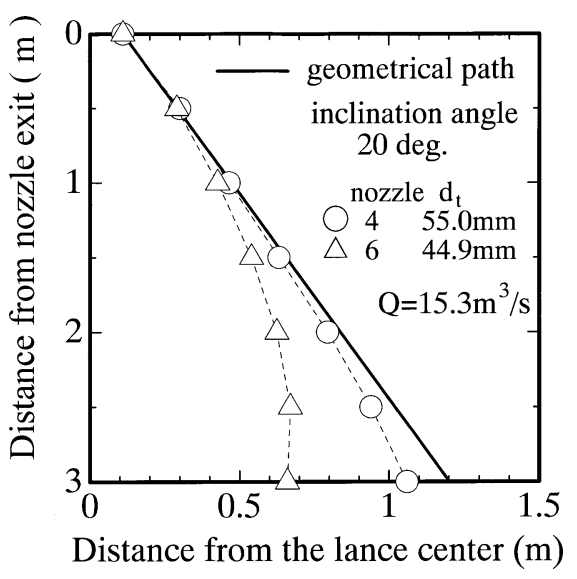

Fig. 15. Effect of the number of nozzles on the jet paths (4- and 6-nozzle lance, inclination angle: 20 degrees).

from the simple geometrical calculation and more aptitude of the coalescence of the jets compared with 4-nozzle lance.

\section{Conclusions}

By the cold model experiment and the flow simulation based on fluid flow analysis, the behavior of jets were investigated using single-nozzle and multi-nozzle lances in the top blown process. The results obtained are as follows:

(1) The calculated core length of the jets from the single nozzle lances coincided with the measured results with a high accuracy.

(2) It is clarified by the fluid flow analysis that the higher ambient temperature leads to the lower density and the higher velocity of the gas jets, but does little affect the dynamic pressure.

(3) In the multiple jets, the RSM is more desirable than the $\kappa-\varepsilon$ model as the turbulent model because the anisotropy of the turbulence could not be ignored in such jets.

(4) The fluid flow analysis was found to be an useful method to predict the effect of the inclination angle and the number of the nozzles on the jet behavior in the top blown processes on a commercial basis.

\section{REFERENCES}

1) Y. Higuchi and Y. Tago: Tetsu-to-Hagané, 86 (2000), 654.

2) A. Masui, W. Wnzel and F. R.Block: Tetsu-to-Hagané, 57 (1971), S404.

3) H. Ishikawa, S. Mizoguchi and K. Segawa: Tetsu-to-Hagané, 58 (1972), 76.

4) S. Kitamura and K. Okohira: Tetsu-to-Hagané, 76 (1990), 199.

5) R. B. Banks and D. V. Chandrasekhara: J. Fluid Mech., 15 (1963), 13.

6) E. T. Turkdogan: Chem. Eng. Sci., 21 (1966), 1133.

7) A. Chatterjee and A. V. Bradshaw: J. Iron Steel Inst., 3 (1972), 179.

8) M. Mori, I. Kobayashi, T. Nakajima, S. Ogino and G. Yoshida: Tetsuto-Hagané, 70 (1984), S244.

9) K. Maya, S. Fukagawa and S. Masuda: CAMP-ISIJ, 6 (1993), 192.

10) M. Hirai, R. Tsujino, T. Ohno, N. Ishiwata and T. Inoshita: Tetsu-toHagané, 74 (1988), 1954.

11) Y. Higuchi and Y. Tago: ISIJ Int., 41 (2001), 1454.

12) M. Shimada, M. Ishibashi and H. Morise: Seitetsu Kenkyu, 266 (1969), 8855.

13) K. Kawakami: Tetsu-to-Hagané, 51 (1965), 708.

14) K. Naito, Y. Ogawa, T. Inomoto, S. Kitamura and M. Yano: ISIJ Int., 40 (2000), 23.

15) B. E. Launder and D. B. Spalding: Lectures in Mathematical Models of Turbulence, Academic Press, London, (1972), 90.

16) B. E. Launder, G. J. Reece and W. Rodi: J. Fluid Mech., 68 (1975), 537.

17) F. S. Lien and M. A. Leschziner: Comput. Fluids, 23 (1994), 983.

18) B. E. Launder : Int. J. Heat Fluid Flow, 10 (1989), 282.

19) S. Sarkar and L. Balakrishnan: ICASE Report, NASA CR 182002 , NASA Langley Research Center, Hampton, (1990).

20) I. Sumi, R. Kawabata, Y. Kikuchi, H. Igarashi, H. Nakabayashi and N. Kobayashi: CAMP-ISIJ, 14 (2001), 876. 